\title{
Estratégias de difusão da educação em museus por meio da escrita: a atuação do Museu Histórico Nacional em seu Anais e na Revista do Ensino
}

Strategies for diffusing education in museums by means of writing: the performance of the National Historical Museum in its Annals and in the Revista do Ensino

Estrategias de difusión de la educación en museos a través de la escritura:

la actuación del Museo Histórico Nacional en su Anales y en la Revista do Ensino

Ana Carolina Gelmini de Faria

Universidade Federal do Rio Grande do Sul (Brasil)

https://orcid.org/0000-0003-0727-9991

http://lattes.cnpq.br/9506092922437967

carolina.gelmini@ufrgs.br

\section{Resumo}

O presente trabalho se propõe refletir, a partir de publicações do autor Roger Chartier, como o mesmo aprofunda a investigação sobre a composição dos textos nas materialidades que os dão a ler, enfatizando aspectos que intencionam a liberdade cerceada do leitor (tais como o autor, as formas tipográficas e os protocolos de leitura). Como aproximação do exercício empírico elejo um texto de uma funcionária do Museu Histórico Nacional, Sigrid Pôrto de Barros, sobre educação em museus que foi publicado em dois suportes diferentes - os Anais do Museu Histórico Nacional e a Revista do Ensino do Rio Grande do Sul - servirá de apoio para a construção da análise. Conclui que o sentido do texto não é indiferente à materialidade do objeto que o comunica, ou seja, a forma transforma o sentido do escrito.

Palavras-chave: História da Cultura Escrita. Museu Histórico Nacional. Revista do Ensino. 


\begin{abstract}
The present work aims to reflect, based on publications by author Roger Chartier, how it deepens the investigation on the composition of the texts in the materialities that make them read, emphasizing aspects that intend the curtailed freedom of the reader (such as the author, typographic forms and reading protocols). As an approximation of the empirical exercise, I chose a text by an employee from the National Historical Museum, Sigrid Pôrto de Barros, about education in museums, which was published in two different supports - the Annals of the National Historical Museum and the Revista do Ensino of Rio Grande do Sul - it will serve as support for the construction of the analysis. It concludes that the meaning of the text is not indifferent to the materiality of the object that communicates it, that is, the form transforms the meaning of the writing.
\end{abstract}

Keywords: History of Written Culture. National Historical Museum. Revista do Ensino.

\title{
Resumen
}

El presente trabajo se propone reflexionar, a partir de publicaciones del autor Roger Chartier, como el mismo profundiza la investigación sobre la composición de los textos en las materialidades que los dan a leer, enfatizando aspectos que pretenden la libertad cercenada del lector (tales como el autor, las formas tipográficas y los protocolos de lectura). Como aproximación al ejercicio empírico elijo un texto de una funcionaria del Museo Histórico Nacional, Sigrid Pôrto de Barros, sobre educación en museos que ha sido publicado en dos soportes diferentes - los Anales del Museo Histórico Nacional y la Revista do Ensino de Rio Grande do Sul - servirá de apoyo para la construcción del análisis. Concluye que el sentido del texto no es indiferente a la materialidad del objeto que lo comunica, es decir, la forma transforma el sentido del escrito.

Palabras clave: Historia de la Cultura Escrita. Museo Histórico Nacional. Revista do Ensino. 


\section{Os textos não são estáveis}

Os textos não são estáveis. Esta oração é um grande exercício de problematização e desconstrução sobre como concebemos as práticas de leitura e escrita ao longo da História. Nesse sentido, o autor Roger Chartier contribui com uma extensa investigação na perspectiva da História Cultural, aprofundando focos de interesse que, como peças de um quebra-cabeça, nos instigam a compor um conjunto de pressupostos para a interpretação da história da cultura escrita: os sujeitos envolvidos, os suportes e usos, os protocolos de leitura, as maneiras de ler, os limites transgredidos e as liberdades refreadas são, por exemplo, reflexões que permitem compreender o lugar da escrita na produção dos saberes.

A proposta deste artigo é apresentar alguns dos conceitos trabalhados pelo autor ao longo de sua trajetória acadêmica e, em um estudo aplicado, articular os eixos de atenção do autor com um texto produzido por uma funcionária do Museu Histórico Nacional e publicado em dois diferentes suportes: os Anais da Instituição e a Revista do Ensino. Nesse sentido, algumas questões suscitam: As características morfológicas do impresso influenciam a apropriação do escrito? A intenção de difusão e uso do texto é igual nas duas publicações? Ou seja, é o mesmo texto?

Cabe apresentar os dois veículos de comunicação impresso. O corpo funcional do Museu Histórico Nacional, ao contrário de outras instituições culturais, teve a preocupação de registrar e disseminar os trabalhos e conhecimentos produzidos. Assim, a escrita, por exemplo, foi um importante aliado para preservar sob a perspectiva da instituição suas ações ao longo de sua trajetória, bem como inserir o próprio museu nas discussões das diferentes áreas que permeiam o campo dos museus em perspectiva nacional e internacional.

Desde sua fundação, em 1922, foi previsto em regulamento a publicação dos Anais do Museu Histórico Nacional, sendo este um espaço para os próprios funcionários apresentarem suas contribuições na construção de conhecimento. Embora somente publicado a partir da década de 1940, os Anais se tornaram um canal fundamental para a construção da história institucional do Museu, reconhecido como um instrumento de disseminação das suas concepções museológicas e, consequentemente, da perspectiva e potencial educativo que a equipe idealizava em suas ações.

Conforme Moreira (2006) analisa, os artigos produzidos pela equipe do Museu Histórico Nacional contribuíram para legitimar a história contada a partir da cultura material, construindo uma escrita de valorização do pioneirismo da instituição, produzindo tanto uma memória da instituição como a disseminação de um perfil científico às experiências museológicas. Através dos artigos publicados nos Anais do Museu Histórico Nacional três profissionais da equipe se destacam em reflexões sobre a relação museu e educação em meados do século XX: Nair Moraes de Carvalho, Sigrid Pôrto de Barros e Dulce Cardozo Ludolf (FARIA, 2013).

Porém, entre as três funcionárias, nos relatórios anuais a conservadora de museus ${ }^{1}$ Sigrid Pôrto de Barros era a apontada como a que mais se envolvia com o atendimento ao público, em específico o acompanhamento em visitações. Um dos desdobramentos futuros desta iniciativa foi sua indicação para ser chefe da Seção de Pesquisa e Assistência Pedagógico-Museográfica da Divisão de Atividades Educacionais e Culturais do Museu Histórico Nacional em 1977 (SÁ; SIQUEIRA, 2007).

Sigrid Pôrto de Barros iniciou em 1947 o Curso de Museus, formando-se em 1949. Principiando seus trabalhos no Museu Histórico Nacional em 1953, desde o relatório anual da

1 O Curso de Museus, fundado em 1932 no Museu Histórico Nacional, visava formar profissionais especializados para o trabalho nos museus com o título de conservadores(as) de museus. Somente em 1966 que esses formandos(as) passaram a ser oficialmente intitulados de museólogos(as). 
instituição de 1956 há evidências que a funcionária tem a educação em museus como centralidade de sua atuação (BRASIL, 1957), compartilhando suas proposições não só entre o corpo funcional, mas também em artigos nos Anais do Museu Histórico Nacional e em revistas da área da Educação, como a Revista do Ensino do Rio Grande do Sul.

A Revista do Ensino do Rio Grande do Sul compunha os veículos de imprensa pedagógica, ou seja, fazia parte do conjunto de periódicos que, formulada por professores para professores, ou mesmo alunos para seus pares ou professores "[...] visam principalmente guiar [a] prática cotidiana, oferecendo informações sobre o conteúdo e o espírito dos programas oficiais, a conduta em classe e a didática das disciplinas" (BASTOS, 2007, doc. eletr.). A Revista do Ensino, segundo Bastos, Lemos e Busnello (2007) tinha por objetivo orientar a professora, em especial a do ensino primário, ao saber pedagógico científico e instrumental, disponibilizando para os leitores diretrizes, legislações, materiais didáticos, por exemplo:

Dessa forma, constituiu-se em um significativo dispositivo de educação do professor, de orientação e direção intelectual e moral, de conformação de suas práticas sociais e escolares, que permite analisar o que se expressam em termos de educativos e pedagógicos, e como atuam como dispositivos e subjetivação da professora moderna (BASTOS; LEMOS; BUSNELLO, 2007, p. 44).

A Revista do Ensino teve duas fases de edição: a primeira compreende os anos de 1939 a 1942 e, a segunda, de 1951 a 1978. Sua trajetória revela a importância no meio educacional, tendo como picos de tiragens a marca de 50 mil exemplares no início da década de 1960, não só mais se limitando ao Rio Grande do Sul - sua repercussão era regional, nacional e internacional (BASTOS; LEMOS; BUSNELLO, 2007).

Assim, ao aproximar os dois suportes que supostamente veiculam o mesmo texto, a composição dos argumentos apresentados irá contribuir para a análise da hipótese: O sentido não está totalmente no texto, os objetos que fornecem a leitura contribuem na produção de sentidos, ou seja, jogam decisivamente na apropriação que dele é feita pelos leitores.

\section{Papéis atribuídos ao escrito}

Roger Chartier, ao investigar o lugar do escrito nas relações entre os homens e na produção dos saberes, apresenta diferentes pressupostos para compreender a história das práticas de leitura e escrita. A construção que tece não é a história do livro, ao contrário, esse é um dos diversos suportes que dão a ler o texto. Segundo o autor, é importante ter consciência que as formas produzem sentidos e um texto, por mais que pareça estável, convida o leitor a interpretações que podem ser diferenciadas devido ao status inédito que o suporte proporciona (CHARTIER, 1998c).

Ainda que considere que cada leitor produz uma apropriação inventiva do texto que recebe, Chartier (1996, p.20) pondera que todo escrito possui uma proposta de leitura: "Que seja explicitamente afirmada pelo escritor ou produzida mecanicamente pela maquinaria do texto, inscrita na letra da obra como também nos dispositivos de sua impressão". A construção do sentido do texto e o seu suporte possuem intenções e convenções, bem como exigem hábitos e competências para as práticas de leitura. A liberdade do leitor jamais é absoluta. O autor, a intenção editorial, os protocolos de leitura e os dispositivos tipográficos são elementos centrais para a discussão do que o autor intitula como "mundo do texto".

Segundo Chartier, na publicação Práticas de leitura (1996, p.96), as orientações que o autor produz no texto para a condução da leitura são relevantes para a investigação do papel 
atribuído ao texto: "Essas instruções, dirigidas claramente ou impostas inconscientemente ao leitor, visam a definir o que deve ser uma relação correta com o texto e impor seu sentido". $\mathrm{Na}$ publicação A aventura do livro: do leitor ao navegador (1998a) reforça, a partir de Foucault, que em certos gêneros, para circularem e serem recebidos há necessidade de uma identificação fundamental dada pelo nome de seu autor, enquanto em outros não. No primeiro caso, muitas vezes a figura do autor legitima a decisão de ler um texto, bem como estimula o leitor na apropriação de sentidos e em seus múltiplos usos.

O texto acadêmico é um exemplo da valorização da autoria. É interessante observar as premissas de Chartier para analisar um texto produzido por Sigrid Pôrto de Barros, antiga funcionária do Museu Histórico Nacional. A princípio elaborado em 1948, mas somente publicado em 1958², Barros escreveu para os Anais do Museu Histórico Nacional, um texto intitulado $O$ Museu e a criança. Cabe destacar que uma das políticas da produção dos Anais era que os textos publicados fossem do próprio corpo funcional, legitimando as pesquisas e ações produzidas na instituição. O texto visa apresentar o planejamento de trabalhos em visitas ao Museu Histórico Nacional, especificamente para o curso primário. Assim, apresenta métodos sugeridos para cada série escolar estimando atividades atraentes e participativas. Em 1963, uma síntese do texto foi publicada na Revista do Ensino. A experiência prática e reflexiva da autora legitimou seu texto a ser compartilhado enquanto proposta de orientação de visita a museus históricos? O texto, ao ter sua difusão na Revista, sofreu adaptações. Seriam as mesmas intenções e propostas dadas a ler nos diferentes suportes?

Embora sejam as mesmas palavras, ao aproximar o formato dos suportes a sensação é que não é o mesmo texto. E, segundo Chartier, não é. Somando-se ao autor, a intenção editorial reforça um sentido dado ao texto e a liberdade cerceada do leitor: as formas discursivas e materiais dos textos lidos reforçam, pelos códigos e convenções, as limitações que regem as práticas de leitura (CHARTIER, 1998a; 1998c).

De acordo com Chartier (1998a, p.53), o editor é um "[...] empreendedor singular que se vê também como um intelectual e cuja atividade se faz em igualdade com a dos autores; daí, aliás, suas relações frequentemente difíceis e tensas". Portanto, sua participação na prática da escrita torna-se tão significativa quanto as operações realizadas pelo autor: "[...] a disposição e a divisão do texto, sua tipografia, sua ilustração. Esses procedimentos de produção de livros não pertencem à escrita, mas à impressão [...] e podem sugerir leituras diferentes de um mesmo texto" (CHARTIER, 1996, p.97).

Para compreender quais mecanismos produzem uma intenção nos usos do objeto impresso, maneiras de ler e formas de apropriação da leitura, Roger Chartier formulou uma expressão para compreender a ordem do texto: os protocolos de leitura.

Os protocolos de leitura delimitam o sentido do texto a ser dado pelo leitor. Podem ser internos ao texto, elaborados pelo autor estimulado por uma vontade disciplinante, ou atribuídas no impresso pela sua edição, composição, impressão por meio da tipografia, conferidas pela intenção editorial. Portanto, os protocolos de leitura podem ser concebidos tanto pelo autor como pelo editor.

Orientações na produção de significações, os protocolos de leitura podem possuir diferentes intenções: interpretativa, complementar, ilustrativa, persuasiva, efeito de realidade ao texto. Encontra-se um protocolo de leitura, por exemplo, nas citações, em termos conclusivos, em notas de rodapé, na didatização do texto, em uma ilustração:

\footnotetext{
${ }^{2}$ As defasagens entre a edição do volume e a real publicação dos Anais do Museu Histórico Nacional se tornaram recorrentes até o ano de 1964, ainda divulgando artigos que foram escritos em 1953, devido à obrigatoriedade de espera na lista de atendimento da Imprensa Nacional, editora do periódico. Nas capas há o registro dos dois anos, no caso do objeto de estudo 1948, ano da organização do volume, e 1958, ano de sua impressão. No artigo ambos os anos serão evidenciados, sendo em colchetes o ano original da produção do texto.
} 
Com efeito, podemos definir como relevante à produção de textos as senhas, explícitas ou implícitas, que um autor inscreve em sua obra a fim de produzir uma leitura correta dela, ou seja, aquela que estará de acordo com sua intenção. (CHARTIER, 1996, p.96)

Os protocolos de leitura são significativos no texto de Sigrid Pôrto de Barros. O primeiro a destacar, provavelmente desenvolvido pelo editor, é o título (Figuras 1 e 2). Embora seja a mesma formulação, "O Museu e a Criança", a tipografia utilizada no Anais do Museu Histórico Nacional e na Revista do Ensino mudam de forma radical a percepção do texto: o primeiro, todo composto por letras com serifa, trazem a seriedade do texto datilografado, bem como o tom acadêmico da produção. Já no segundo, a composição trabalhada, em especial na composição O Museu, evoca uma aproximação didática, muito convidativa, atraente, condizente com seu suporte.

Figura 1 -Título "O Museu e a Criança" Anais do Museu Histórico Nacional

\section{O MUSEU E A CRIANÇA}

Fonte: BARROS, 1958 [1948], p.46
Figura 2 - Título "O Museu e a Criança" Revista do Ensino

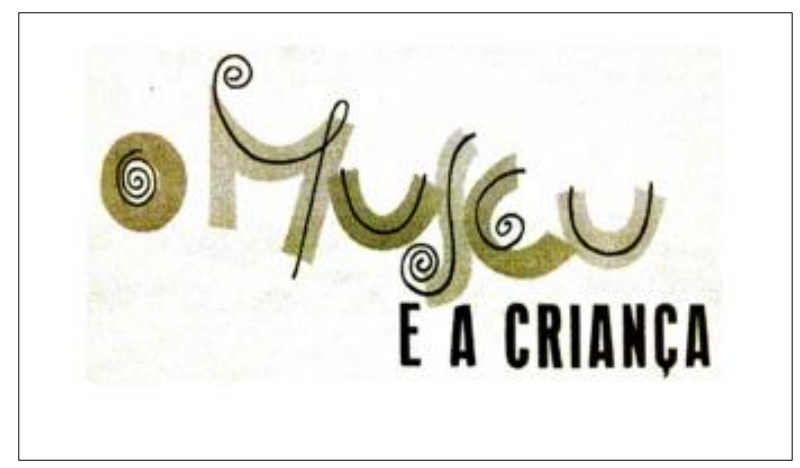

Fonte: BARROS, 1963, p.48

Outro importante protocolo de leitura, possivelmente elaborado tanto pela autora como pelos editores, são as divisões que didatizam o texto. A primeira versão possui, no total, 27 páginas. Na Revista do Ensino, três páginas. Ao analisar com atenção percebe-se que o subtítulo apresentado na Revista, "PLENAJAMENTO DE TRABALHOS DURANTE AS VISITAS DAS DIVERSAS SÉRIES DO CURSO PRIMÁRIO” é, na versão dos Anais, uma das muitas divisões que orientam a leitura do texto. Esta operação de seleção de parte do texto nos provoca a focalizar, segundo Chartier (2004, p.18), a "atenção sobre as práticas particulares, objetos específicos, usos determinados" do texto, seja na perspectiva da vontade dos produtores de discursos e de normas, seja nas apropriações diferenciadas do leitor.

Neste sentido, ao ter como ênfase a subseção do Anais do Museu Histórico Nacional e a matéria da Revista do Ensino percebe-se que, embora sejam as mesmas palavras, sua organização, apresentação e extensão singularizam o mesmo texto (Figuras 3 e 4). Esta impressão se reforça na sua distribuição: a utilização de colunas modifica a forma de ler. Nos Anais, o texto é corrido. Na Revista, a disposição é em três colunas. Como leitora que se debruçou em ambas versões, percebo que na primeira a leitura parece ser mais densa do que na segunda: a linha longa do texto aparenta propagar um conteúdo com maior formulação, enquanto no segundo as linhas curtas possibilitam uma apropriação mais ágil e objetiva, dando mais a sensação de manual do que a versão anteriormente publicada: "A obra não é jamais a mesma quando inscrita em formas distintas, ela carrega, a cada vez, um outro significado" (CHARTIER, 1998a, p.71). 
Figura 3 - Disposição do texto em uma coluna Anais do Museu Histórico Nacional

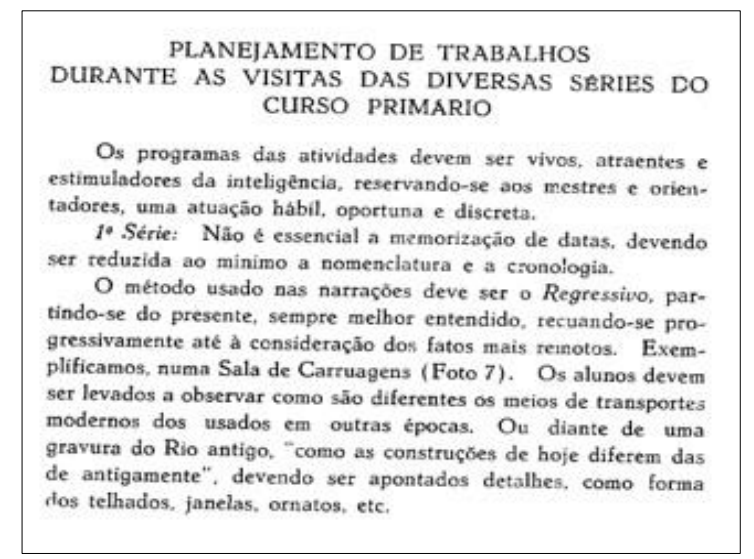

Fonte: BARROS, 1963, p.48.
Figura 4 - Disposição do texto em três colunas Revista do Ensino

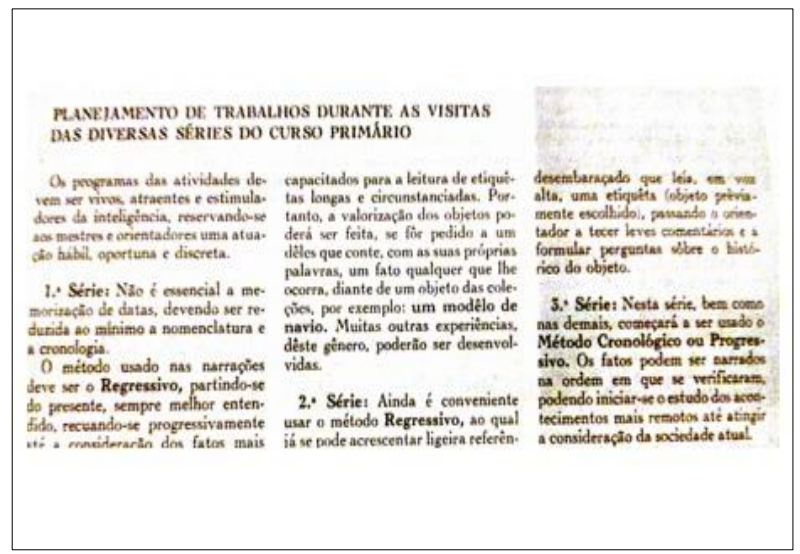

Fonte: BARROS, 1958 [1948], p.63.

Cabe ressaltar que, no texto utilizado como exemplo de análise, há, intencionalmente, uma mudança significativa ao aproximar as versões: a escolha das imagens. Segundo Chartier (1998b), a imagem impressa é pensada e manuseada como um instrumento do conhecimento, tornando-se apta na elaboração da verdade do discurso construído. Associados ao texto, ao conquistar a adesão de quem olha produz persuasão e crença, legitimando-o:

A imagem é muitas vezes uma proposta ou protocolo de leitura, sugerindo ao leitor a correta compreensão do texto, o seu justo significado. [...] ela pode constituir-se num lugar de memória que cristaliza, numa representação única, uma história, uma propaganda, um ensinamento, ou ser então construída como a figura moral, simbólica, analógica, que fornece o sentido global do texto, que uma leitura descontínua e vagabunda poderia fazer perder. (CHARTIER, 1998b, p.15-16)

Roger Chartier, ao analisar o uso da imagem enquanto dispositivo tipográfico (1998b) pondera: o seu significado e papel não são os mesmos quando está dissociada ou inscrita no texto. O uso da imagem como protocolo de leitura pressupõe que o leitor estabeleça abstratamente as relações que lhes dão um sentido.

O mesmo trecho do texto de Barros publicado tanto nos Anais do Museu Histórico Nacional como na Revista do Ensino possui duas imagens como protocolo de leitura. Porém, em cada suporte foram selecionadas fotografias distintas que modificam a construção conceitual e teórica do texto, transformando-o de forma decisiva. Esta operação de seleção e relações propositais colabora para "entendermos de que maneira um mesmo texto, dado a ler sob formas diferentes, pode produzir não só diferentes sentidos como diferentes públicos" (CHARTIER, 2012, p.163). 
Nos Anais do Museu Histórico Nacional as imagens selecionadas e introduzidas no meio do texto (Figuras 5 e 6) são de objetos que fazem parte do acervo da instituição. Cada imagem preenche uma página inteira, obtendo assim, grande destaque. Junto às imagens, as legendas reforçam ainda mais a valorização do bem cultural vinculando-o aos grandes heróis e grandes fatos: $\mathrm{Na}$ fotografia 07 da publicação, que apresenta um transporte terrestre, a legenda "Côche de gala que serviu a D. Pedro II" (Figura 5); na folha seguinte, a fotografia 08 é de uma caneta e a legenda revela: "Caneta oferecida pelo povo, à princesa Isabel para a assinatura da Lei Áurea” (Figura 6).

Figura 5 - Fotografia 7 do artigo do Anais do Museu Histórico Nacional

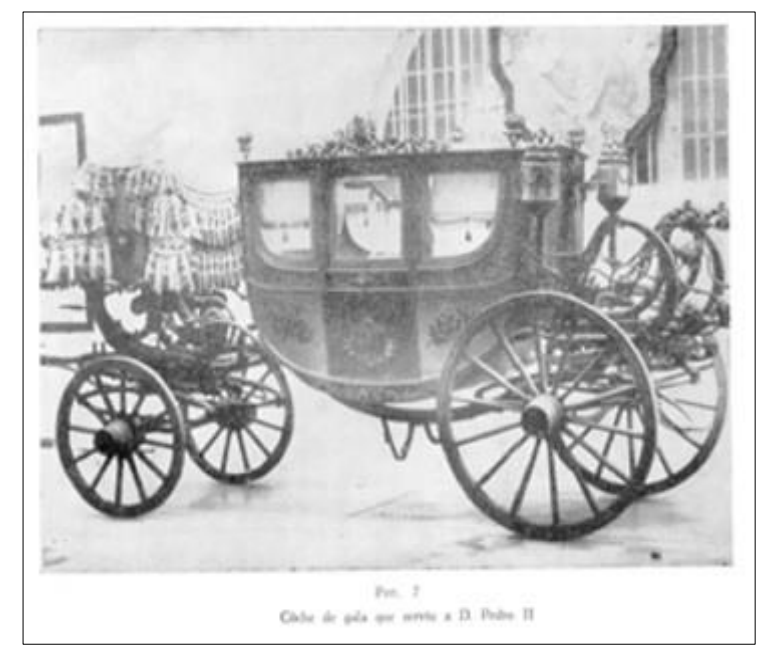

Fonte: BARROS, 1958 [1948], p.64
Figura 6 - Fotografia 8 do artigo do Anais do Museu Histórico Nacional

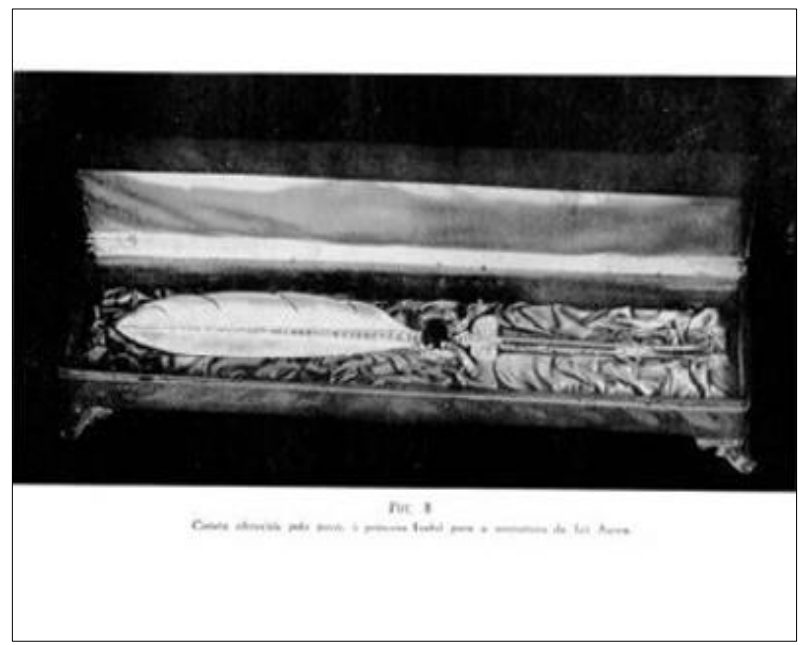

Fonte: BARROS, 1958 [1948], p.654

As apresentações destes objetos, bem como as legendas, valorizam o método lição de coisas nas visitas escolares e reforçam o Museu como a Escola da Pátria ou a Casa do Brasil, títulos que os funcionários e imprensa da época propagavam para estimular a educação cívica.

Ao contrapor as imagens do texto em ambos suportes vem a surpresa: na Revista do Ensino foram selecionadas também duas fotografias. Uma encontra-se na parte superior do texto, ao lado do título, preenchendo parte de duas folhas sequenciais. A segunda compõe metade de uma página. $O$ interessante é observar que são os mesmos objetos apresentados no texto dos Anais, o côche (Figura 7) e a caneta (Figura 8). Porém, a visualização do bem cultural é radicalmente transformada, pois, ao invés da imagem revelar o objeto isolado, capta estudantes interagindo com o patrimônio. Há o toque, uma prática que o processo de salvaguarda inibe na contemporaneidade. Há a expressão da curiosidade, da atenção, qualificando energicamente o uso da proposta do texto, como bem informa o subtítulo: Planejamento de Trabalhos durante as visitas das diversas séries do Curso Primário.

\footnotetext{
3 Transcrição da legenda: "Coche de gala que serviu a D. Pedro II ” (BARROS, 1958 [1948], p.64).

4 Transcrição da legenda: "Caneta oferecida pelo povo, à princesa Isabel para a assinatura da Lei Áurea" (BARROS, 1958 [1948], p.65).
} 
Figura 7 - Fotografia do côche no texto publicado na Revista do Ensino - parte inferior da página

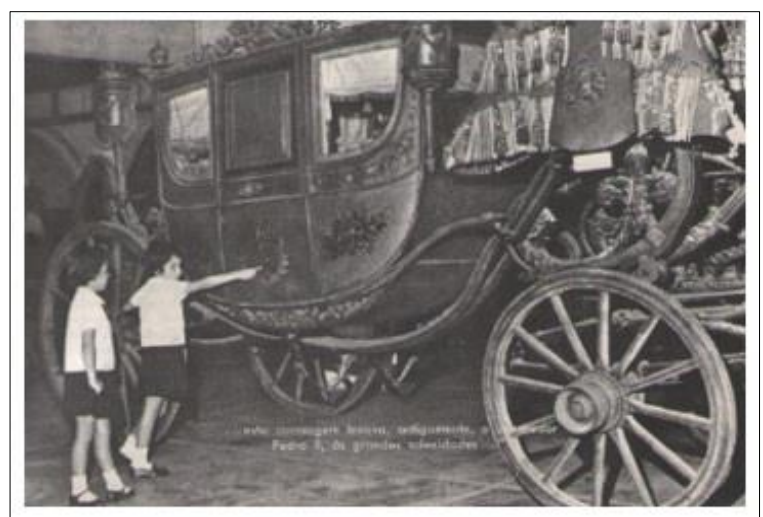

Fonte: BARROS, 1964, p.49
Figura 8 - Fotografia da caneta no texto publicado na Revista do Ensino - no centro de duas páginas

Cabe ainda, ressaltar, que a legenda que acompanha essas fotografias complementa sua ação como protocolo de leitura no interior do texto. A entonação proposta para a leitura da informação apresentada na legenda se modifica pelos códigos textuais que conferem à frase uma espécie de diálogo: o travessão, as aspas, o negrito, as reticências e a troca do termo côche por carruagem potencializam a escrita como uma fala, legitimando a didatização da visita aos museus, reforçada nas imagens dos estudantes, e a interação com o leitor que, no caso da Revista do Ensino, tinha como público alvo o professor: - "Com esta pena a Princesa Isabel assinou a Lei Áurea.” (Figura 8) “...esta carruagem levava, antigamente, o imperador Pedro II, às grandes solenidades...” (Figura 7).

O autor, a intenção editorial, os protocolos de leitura, dentre os quais os dispositivos tipográficos formam uma complexa operação que dá a ler o texto: "As limitações existem, as limitações estão nos textos, nos objetos que veiculam esses textos, nas vozes que enunciam seu sentido" (CHARTIER, 2012, p.167). Porém, embora existam as limitações que pertençam, como refere-se o autor, à ordem do discurso, "[...] um texto só existe se houver um leitor para lhe dar um significado" (CHARTIER, 1998c, p.11). Estes movimentos tornam o texto singular e, ao mesmo tempo, somado às próprias referências do leitor, proporcionam um sentido mais ou menos partilhado aos usos e significações dos papéis atribuídos ao escrito.

\section{Considerações finais - os papéis atribuídos ao escrito}

Um texto, duas impressões em diferentes suportes. Aproximar o que parece ser a mesma escrita, a partir dos pressupostos formulados por Roger Chartier, é propor novas percepções sobre os usos, os manuseios, as formas de apropriação do texto. Nesse sentido, o autor provoca uma orientação de análise das práticas de escrita e leitura centrada nos sujeitos, sejam os criadores das limitações dos sentidos, sejam os leitores que, ao atribuírem sentidos, transgridem as limitações.

O texto de Sigrid Pôrto de Barros se tornou um interessante exemplo de estudo: foi impresso tanto nos Anais do Museu Histórico Nacional, uma publicação científica da instituição no qual os artigos produzidos contribuíram para legitimar a história contada a partir da cultura material, sendo uma ferramenta de propagação de discursos entre os pares (MAGALHÃES, 2006), como na Revista do Ensino do Rio Grande do Sul, um veículo de destaque da imprensa pedagógica, fazendo parte do conjunto de periódicos que, formulada por professores para professores, ou mesmo alunos para seus pares ou professores guiavam a prática cotidiana do 
ensino (BASTOS, 2007). De um texto teórico, com extensas formulações embasadas academicamente sobre a educação em museus passou a ser, pelos protocolos de leitura e o suporte que o veicula, um manual de como realizar visitas educativas em museus.

Vidal e Faria Filho (2005) abordam três vertentes que constituíram a História da Educação no Brasil: a primeira foi marcada pelas contribuições do Instituto Histórico e Geográfico Brasileiro no século XIX e início do século XX, que sistematizaram uma narrativa sobre a prática educacional do País; no segundo momento, os autores destacam as Escolas Normais como um cenário para o estudo da História da Educação, que percebida como uma disciplina integrava as referências teóricas com o cotidiano escolar; e o terceiro importante movimento foi conferido pela escrita acadêmica, tornando a História da Educação um campo de estudo capaz de agregar múltiplos objetos que se relacionam com a aprendizagem e as culturas escolares. Observa-se, pelo viés da História da Educação, que a produção da conservadora de museus Sigrid Pôrto de Barros condiz com o contexto do campo da educação da primeira metade do século XX: a busca da qualificação da educação, ao oportunizar experiências para a vida, seja pelo incentivo artístico, promoção de atividades recreativas socioeducativas e estímulo à extensão cultural. À escola caberia incentivar o próprio aluno a obter o conhecimento, enquanto ao professor era atribuído o papel de facilitador da aprendizagem, aguçando a curiosidade e o interesse.

Um dos desdobramentos no Brasil dessa perspectiva foi o Manifesto dos Pioneiros da Educação Nova: a reconstrução educacional no Brasil, assinado por 26 intelectuais e publicado em 1932. O documento foi considerado um divisor entre educadores conservadores e liberais brasileiros. Peres (2005) observa que a história da Escola Nova, também conhecida como Escola Ativa ou Escola Progressiva, apresenta divergências e discordâncias em relação ao projeto ideológico de escola renovada. Porém, destaca que a reação contra o formalismo e o hábito de colocar a escola à margem da vida eram pressupostos que uniam o movimento de reação. A conservadora de museus Sigrid Pôrto de Barros manifestava por escrito sua vinculação à Escola Ativa, defendendo a educação em museus como processo capaz de contribuir para a transformação da sociedade brasileira. A publicação de seu texto na Revista do Ensino, impresso que tinha um dos públicos-alvo professores normalistas, não é mera coincidência.

Assim, a aproximação aos pressupostos teóricos formulados por Roger Chartier e o ensaio empírico revelam o quanto um texto é dinâmico - a trajetória da formulação, circulação e partilha de um texto demonstram o quanto o ato de escrever e ler são práticas, antes de tudo, culturais. Suas complexas relações estimulam a atenção do pesquisador aos usos, apropriações e atribuições de sentido conferidos aos textos, processos condicionados e, ao mesmo tempo transgredidos, pelos produtores que oferecem à leitura e os leitores que possuem distintas maneiras de ler o texto.

\section{Referências}

BARROS, Sigrid Pôrto. O Museu e a Criança. Anais do Museu Histórico Nacional, vol. IX. Rio de Janeiro: Ministério da Educação e Cultura, 1958. p.46-73. [? 1948]. Disponível em: http://www.docpro.com.br/mhn/bibliotecadigital.html. Acesso em 27 mar. 2020.

BARROS, Sigrid Pôrto. O Museu e a criança. Revista do Ensino, Rio Grande do Sul, v.12, nº94, 1963. p.148-150.

BASTOS, Maria Helena Camara. A imprensa de educação e de ensino: repertórios analíticos. O exemplo da França. Revista Brasileira da Educação, vl.12 n.34. Rio de Janeiro, 2007. DOI: https://doi.org/10.1590/S1413-24782007000100013 
BASTOS, Maria Helena Camara; LEMOS, Elizandra Ambrosio; BUSNELLO, Fernanda. A Pedagogia da Ilustração: uma face do impresso. In: BENCOSTTA, Marcus Ley. Culturas escolares, saberes e práticas educativas. São Paulo: Cortez, 2007. p. 41-78.

BRASIL. Ministério da Educação e Cultura. Museu Histórico Nacional: Guia do Visitante. Rio de Janeiro, 1957. 35p.

CHARTIER, Roger. A cultura do objeto impresso. In: CHARTIER, Roger. As utilizações do objecto impresso. tr. Ida Boavida. Miraflores, Portugal: Difel, 1998b. 437p. p.09-21.

CHARTIER, Roger. Leituras e leitores na França do Antigo Regime. tr. Álvaro Lorencini. São Paulo: Unesp, 2004. 395p.

CHARTIER, Roger. (org). Práticas de leitura. tr. Cristiane Nascimento. São Paulo: Estação Liberdade, 1996. 266p.

CHARTIER, Roger. A aventura do livro o leitor ao navegador. Conversações com Jean Lebrun, tr. Reginaldo Carmello Corrêa de Moraes. São Paulo: Editora Unesp, 1998a. 160p.

CHARTIER, Roger. A Ordem dos livros. Leitores, autores e bibliotecas na Europa entre os séculos XIV e XVIII, tr. Mary del Priore, Brasília: Editora Universidade de Brasília, 2ª ed., 1998c. 111p.

CHARTIER, Roger. Roger Chartier entrevistado por Robert Darton. MATRIZes, Ano 5, $\mathrm{n}^{\circ} 2$. São Paulo, Jan/Jul, 2012. p.159-177. DOI: https://doi.org/10.11606/issn.1982-8160.v5i2p159-177

FARIA, Ana Carolina Gelmini de. O caráter educativo do Museu Histórico Nacional: O Curso de Museus e a construção de uma matriz intelectual para os museus brasileiros (1922-1958), 2013, 234p. Dissertação (Mestrado) - Programa de Pós-Graduação em Educação, Universidade Federal do Rio Grande do Sul, Porto Alegre, 2013. Disponível em: https://www.lume.ufrgs.br/handle/10183/72139. Acesso em: 27 mar. 2020

MAGAlHÃES, Aline Montenegro. Culto da Saudade na Casa do Brasil - Gustavo Barroso e o Museu Histórico Nacional (1922-1959). Fortaleza: Museu do Ceará, Secretaria da Cultura do Estado do Ceará, 2006. 142p. [Outras Histórias, 49].

MOREIRA, Afonsina Maria Augusto. No Norte da Saudade: esquecimento e memória em Gustavo Barroso, 2006, 271p. Tese (Doutorado) - Programa de Pós-Graduação em História, Pontifícia Universidade Católica, São Paulo, 2006. Disponível em: https://tede2.pucsp.br/handle/handle/12939. Acesso em 27 mar. 2020.

PERES, Eliane. A Escola Ativa na Visão de Adolphe Ferrière: elementos para compreender a Escola Nova no Brasil. In: STEPHANOU, Maria; BASTOS, Maria Helena Camara. Histórias e memórias da educação no Brasil, v. III. Petrópolis: Vozes, 2005. p. 114-128.

SÁ, Ivan Coelho; SIQUEIRA, Graciele Karine. Curso de Museus - MHN, 1932-1978: alunos, graduandos e atuação profissional. Rio de Janeiro: Universidade Federal do Estado do Rio de Janeiro, Escola de Museologia, 2007. 258p.

VIDAL, Diana Gonçalves; FARIA FILHO, Luciano Mendes. História da educação no Brasil: a constituição histórica do campo e sua configuração atual. In: VIDAL, Diana Gonçalves; FARIA FILHO, Luciano Mendes (orgs). As lentes da história: estudos de história e historiografia da educação no Brasil. São Paulo: Autores Associados, 2005. p. 73-139. 